\title{
Chidamide Combined with Doxorubicin Induced p53-Driven Cell Cycle Arrest and Cell Apoptosis Reverse Multidrug Resistance of Breast Cancer
}

\section{Lixia CAO}

Tianjin Medical University Cancer Institute and Hospital

\section{Shaorong Zhao}

Tianjin Medical University Cancer institute and Hospital

Qianxi Yang

Tianjin Medical University Cancer Institute and Hospital

Zhendong Shi

Tianjin Medical University Cancer Institute and Hospital

Jingjing Liu

Tianjin Medical University Cancer Institute and Hospital

\section{Teng Pan}

Tianjin Medical University Cancer Institute and Hospital

\section{Dongdong Zhou}

Tianjin Medical University Cancer Institute and Hospital

Jin Zhang ( $\nabla$ zhangjintjmuch1@163.com)

Tianjin Medical University Cancer institute and Hospital https://orcid.org/0000-0001-7241-0760

\section{Primary research}

Keywords: Breastcancer,Histonedeacetylase,Chidamide,multidrug-resistant

Posted Date: September 2nd, 2020

DOI: https://doi.org/10.21203/rs.3.rs-67615/v1

License: (1) (1) This work is licensed under a Creative Commons Attribution 4.0 International License.

Read Full License

Version of Record: A version of this preprint was published at Frontiers in Oncology on March 2nd, 2021. See the published version at https://doi.org/10.3389/fonc.2021.614458. 


\section{Abstract}

Background The multidrug-resistant (MDR) phenotype is usually accompanied by an abnormal expression of histone deacetylase (HDAC). Given that HDAC is vital in chromatin remodeling and epigenetics, inhibiting the role of HDAC has become an important approach for tumor treatment. However, the effect of HDAC inhibitors on MDR breast cancer has not been elucidated. This study aimed to evaluate the resistance of two MDR breast cancer cell lines to the HDAC-selective inhibitor chidamide $(\mathrm{CHI})$.

Methods Cell viability, cell cycle and apoptosis were detected by CCK8, crystal violet staining, EDU staining, TUNEL assay, flow cytometry. The expression of HDAC1, H3K9, H3K18, p53, p21, caspase3/7/9 and the Bcl family was analyzed by western blotting and Quantitative real-time PCR. MDR breast cancer growth suppression by $\mathrm{CHI}$ and/or doxorubicin (DOX) in vivo was investigated in a tumor xenograft mouse model.

Results The results showed that, $\mathrm{CHI}$ combined with DOX showed significant cytotoxicity to MDR breast cancer cells in vitro and in vivo compared with the $\mathrm{CHI}$ monotherapy. The cell cycle distribution results showed that $\mathrm{CHI}$ caused G0/G1 cell cycle arrest and inhibited cell growth regardless of the addition of DOX. At the same time, Annexin $\mathrm{V}$ staining and TUNEL staining results showed that $\mathrm{CHI}$ enhanced the number of cell apoptosis in drug-resistant cells. The western blot analysis found that p53 as a tumor suppressor was in a silent state in drug-resistant cells. However, p53 was activated in the CHI-treated and combined treatment groups, which, in turn, activated the p53 up-regulated apoptosis regulator recombinant protein (Puma) and pro-apoptotic protein Bax, downregulated the apoptotic proteins $\mathrm{Bcl}-\mathrm{xL}$ and $\mathrm{Bcl}-2$, and activated the caspase cascade to induce apoptosis.

Conclusion The irreversible cell stress induced by $\mathrm{CHI}$ combined with DOX reduced the expression of HDAC1 and activated caspase-dependent apoptosis and p21-mediated growth arrest pathway, which might have been driven by the activation of $\mathrm{p} 53$. This provided a strong theoretical basis for exploring the treatment strategy of the combined use of $\mathrm{CHI}$ in patients with breast cancer who did not respond to chemotherapy or had cancer progression.

\section{Full Text}

This preprint is available for download as a PDF.

\section{Tables}

Due to technical limitations, table $1 \& 2$ is only available as a download in the Supplemental Files section.

\section{Supplementary Files}

This is a list of supplementary files associated with this preprint. Click to download. 
- 3AdditionalFile1.tif

- 4Table2.tif

- 4Table1.tif 